MATEC Web of Conferences 53, 01006 (2016)

DOI: $10.1051 /$ matecconf/20165301006

(C) Owned by the authors, published by EDP Sciences, 2016

\title{
Reinforcement of concrete structures by fiberglass rods
}

\author{
Arina Avdeeva ${ }^{1, a}$, Inga Shlykova ${ }^{1}$, Maria Antonova ${ }^{1}$, Yuri Barabanschikov ${ }^{1}$ and Svetlana Belyaeva ${ }^{1}$ \\ ${ }^{1}$ St.Petersburg State Polytechnical University, 195251, St.Petersburg, Russia
}

\begin{abstract}
In this article we introduced conducted experiments to determine the basic characteristics of composite reinforcement fiberglass reinforcement on the example of the same diameter, but with a different number of rovings. We have established strength along the reinforcing fiber and the corresponding class of the steel reinforcement.
\end{abstract}

\section{Introduction}

Corrosion is the main drawback of steel. Fiberglass solves this problem. Corrosion resistance is one of the main advantages of composite reinforcement. The others are: increased resistance to tearing, light weight (fiberglass is up to 9 times lighter than steel), chemical resistance, good elastic properties, frost (up to $-70 \mathrm{C}^{\circ}$ ) and heat (up to $100 \mathrm{C}^{\circ}$ ) resistance, low thermal and zero electrical conductivity, radio transparency [1-4]. These features make possible to use this type of reinforcement in the aggressive environment [5].

Building armature is used to manufacture all the types of concrete structures. Fittings in cooperation with concrete resist tensile load $[6,7]$.

The usages of composite reinforcement can significally reduce the weight of structures, increase to aggressive environments, expand architectural features, and reduce labor costs [8,9].

The application of the framework structures improves physical and mechanical properties, reduces strains on building elements $[10,11]$.

The advantages of fiberglass reinforcement in comparison with conventional metal alloys the higher values of tensile strength and fatigue limits $(10-50 \%)$, better elasticity, stiffness and reduced crack tendency $[12,13]$. The usage of composite reinforcement increases rigidity of structure and saves metal [14-16].

Non-metallic reinforcing consists of the fiber bundle situated along the rod and interconnected by the polymer resin (cured thermoset) [17]. Bundle of fiber of smaller diameter is wrapped around the main stem in order to increase adhesion [18-20]. There are two types of non-metallic fittings depending on the type of fiber material that was used in manufacturing: glass and basaltic ones. Every type has its own distinctive features. Fittings are available in the form of different shaped rods. They are subdivided by the outer diameter and the rod length [21].

The need to ensure magnetic and dielectric properties of some products and facilities as well as an expanding use of reinforced concrete operated in aggressive environments stimulated interest to fiberglass reinforcement in the 60s [22].

\footnotetext{
${ }^{\text {a }}$ Corresponding author : arina.avdeeva@rambler.ru
} 
Composite rebar is currently becoming an irreplaceable building material thanks to its distinctive properties. It is used to reinforce concrete and ferroconcrete, thin-wall structures, to repair structures damaged by exposure to corrosive environments [23]. Composite rebar is also used along with slag cement; pozzolanic cement; mixed binder (with the high content of active mineral additives); antifreeze additives; porous and coarse-pored concrete; light and cellular concrete [24]. Its field of usage also comprises monolithic construction, reinforced brickwork, construction of seaports and tunnels $[25,26]$.

Buildings can be reinforced both internal (fiberglass rebar (FRP) is embedded in the concrete) and external (fiberglass lattice is situated in the surface of construction and covered by sprayed plaster). The two types of reinforcement can be implemented simultaneously. As a result, the service life of construction lasts up to 80 years [21].

Fiberglass in the forms of non-woven geotextiles, geogrid and lattice is used in road construction. These components make roadbed more durable and reliable [27, 28]. They also reduce the thickness of paving [29].

The work is based on experimental investigation of physical, chemical and mechanical properties of two specimens of concrete (reinforced with polymer armature and concrete without reinforcement). Investigations show that toughness of specimens reinforced with polymeric beams is two times higher, flexural strength increases by $40 \%$ [30].

\section{Materials and Methods}

Fiberglass reinforcement produced by OOO "PROF". Test material was reinforced in one direction. Four compositions of reinforcement were tested. They had 17, 18, 19 and 20 rovings respectively. All the samples had a diameter of $8 \mathrm{~mm}$. The results obtained from the tests (Tab. 1) show that increasing number of rovings increases weight content of fiber glass the sample. The volume content of filler in composition with 18 rovings is the same as in composition with 19 due to porosity of material. Ignition of sample leads to weight reduction (burned binder) and volume reduction (binder and pores). Porosity also causes discrepancy between volume and mass content of fiberglass in these samples. It is shown by the results of the experiments (Tab. 1).

Early fracture of rod ends hindered the investigation. The following methods helped us to overcome this problem. The diameter of $10 \mathrm{~mm}$ length middle part of the sample was reduced to 5 $\mathrm{mm}$. Ends of the sample were wound with several layers of glass fiber with polyester resin.

Table 1. Indicators properties of fiberglass reinforcement a diameter of $8 \mathrm{~mm}$

\begin{tabular}{|c|c|c|c|c|}
\hline \multirow{2}{*}{ Name indicator } & \multicolumn{3}{|c|}{ Number roving } \\
\cline { 2 - 4 } & $\mathbf{1 7}$ & $\mathbf{1 8}$ & $\mathbf{1 9}$ & $\mathbf{2 0}$ \\
\hline Weight content of glass fiber, [\%] & 78.3 & 81.5 & 82.6 & 85.6 \\
\hline Volume content of glass fiber Z, [\%] & 58.5 & 64.1 & 64.1 & 70.0 \\
\hline FRP density $\gamma,[\mathrm{g} / \mathrm{cm} 3]$ & 1.971 & 2.076 & 2.048 & 2.160 \\
\hline Water Absorption by weight Ww, [\%] & 1.55 & 0.54 & 1.76 & 0.94 \\
\hline Water Absorption by volume Wv, [\%] & 3.05 & 1.12 & 3.61 & 2.03 \\
\hline Common porosity Pc, [\%] $]$ & 7.86 & 5.67 & 7.86 & 5.47 \\
\hline Semi-closed porosity Pcl, [\%] & 4.82 & 4.55 & 4.26 & 3.44 \\
\hline Breaking strength Rp, [MPa] & 881 & 922 & 870 & 967 \\
\hline Relative breaking elongation, [\%] & 1.97 & 1.80 & 1.73 & 1.71 \\
\hline Tensile modulus, [GPa] & 46.0 & 52.8 & 51.8 & 58.5 \\
\hline Compression strength Rcom, [MPa] & 221 & 311 & 260 & 273 \\
\hline Flextural strength Rben, [MPa] & 267 & 310 & 287 & 340 \\
\hline Tensile strength (fracture), [MPa] & 15.0 & 15.0 & 14.6 & 15.6 \\
\hline Shear strength, [MPa] & 30.5 & 35.4 & 34.2 & 35.2 \\
\hline LTEC, $10-6 /\left[{ }^{\circ} \mathrm{C}\right]$ & 4.51 & 4.74 & 4.83 & 4.57 \\
\hline
\end{tabular}




\section{Results and Discussion}

From Table 1 it is seen, that tensile strength by tension increases with the percentage of reinforcement. However, the tensile strength by break of samples 19 was less than that 18 , which appears to be due to a lower density 19. Point 19 for breaks quite clear linear dependence of the strength of the density fiberglass reinforcement. With the exclusion of the point correlation coefficient, which is defined by the formula:

$$
K^{2}=1-\frac{\Sigma\left(R_{i}-R_{i}{ }^{e}\right)^{2}}{\left[\frac{\left(\Sigma R_{i}^{2}\right)-\left(\Sigma R_{i}\right)^{2}}{n}\right]}
$$

It increases from 0.751 to 0.992 . Similarly, the dependence of tensile strength by break of the volume content fiber becomes sufficiently strict linearity $\left(\mathrm{K}^{2}=0.9999\right)$ with the exception of it to the point 19. When accounting for 19 of the correlation coefficient decreases to a value of 0.6453 .

Character discontinuity bars fiberglass reinforcement has its own characteristics. In areas of stress concentration consistently produces local discontinuities of individual fibers or bundles, accompanied by a brief drop and subsequent increase of the load. This character is due to unequal tension of the fibers when the stress is perceived only the most intense of them, and as they discontinuity force is transmitted to other fibers.

Tensile strength of rods with reduced diameter $(5 \mathrm{~mm})$ is slightly less than the same characteristic of full diameter rods $(8 \mathrm{~mm})$. It corresponds to the well known idea of influence of scale factor, which equeals to the ratio between strength of samples with the diameter of $8 \mathrm{~mm}$ ad samples with the diameter of $5 \mathrm{~mm}$.

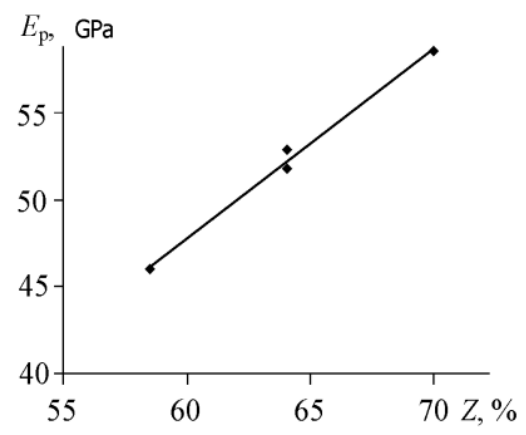

Figure 1. The dependence modulus of elasticity by tension FRP on the degree of reinforcement

In determining the elastic modulus of the samples was carried out loading steps of $250-300 \mathrm{~kg}$. The deformation was measured with a device on the indicator of hour type with an accuracy of 1 micron. At each stage of loading or excerpts for 25 minutes. Exposure due to the need to stress relaxation characteristic of fiberglass reinforcement. Modulus of elasticity of volume content of the reinforcing filler is shown in Fig. 1. When exposed to a particular stage of the loading tension decay over time as shown in Fig. 2 wherein the ordinate the proportion relative to the initial tension value $\sigma_{0}$, i.e. relation $\sigma / \sigma_{0}$. As can be seen from Fig. 2, after $25 \mathrm{~min}$. tension in samples average about $70 \%$ of $\sigma_{0}$. In the presented experiments $\sigma_{0}$ for different samples varied from 344 to $466 \mathrm{MPa}$. Despite this, the relative values of $\sigma / \sigma_{0}$, as for the individual samples and the average for the series of largely coincided. At the same time, a decrease in the tension drop across the length of the sample, so that the elastic modulus in the relaxation process is kept constant. 


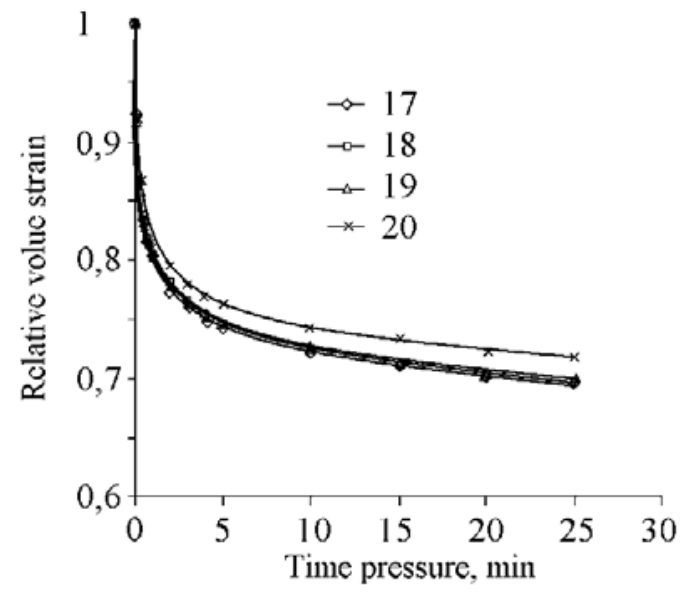

Figure 2. Relaxation in FRP

When the samples were compressed in parallel to grain, the destruction was accompanied by formation of longitudinal cracks, passing through the bond between fibers. Lack of reinforcement explains constant character of splitting strength. Similar results were obtained in case of chipping (in parallel to grain). In both cases only the resin resists the destruction of sample.

\section{Conclusion}

LTEC was determined by a quartz dilatometer. The samples were $100 \mathrm{~mm}$ long. The temperature was varied from $20^{\circ} \mathrm{C}$ to $80^{\circ} \mathrm{C}$. The linear dependence is observed for elongation of the samples. Also, the elongation does not depend on the nature and density of the reinforcing filler. The content of the reinforcing filler in percent and the porosity affect the strength as a result of incomplete infiltration of the filler. By increasing the reinforcing fibers in the reinforcement reduces deformation properties. The break the binder between fibers caused by tensile stresses. Therefore, the strength of the resin acting as a binder characterize experiments on shear fracture along the fibers and tensile by shear fracture. The strength along the of the reinforcing fibers above tensile strength across the fibers. The degree of reinforcement does not depend on water absorption.

FRP strength corresponds to the class steel reinforcement Am-IV, at the same time characterized by low modulus values (3.5 times), LTEC (2.5 times) and elongation (4-5 times).

\section{References}

1. A.S. Boldyrev, P.A. Zolotov, A.N. Lusov, Building materials: directory (Stroyizdat, Moscow, 1989)

2. R. Kamnik, B. Kovačič, B. Pribicević, A. Đapo, Geodetski List, 69 (3), 171-188 (2015)

3. S.A. Elders, A.A. Sundukova, Strengthening masonry composite materials and screw rods (State Technical University, Moscow, 2011)

4. J. Frank, Reinforced plastics composites (Univ of Sheffield, London, 2013)

5. N.P. Frolov, Fiberglass reinforcement and fiberglass concrete construction (Stroyizdat, Moscow, 1980)

6. N. Gubeljak, J. Predan, D. Kozak, J. Tuma, B. Kovačič, P. Konjatić, J. Sertić, Strojarstvo, 51 (4), 263-271 (2009)

7. S.V. Klyuyev, Magazine of Civil Engineering, 8, 61-103 (2012)

8. O.N. Stolyarov, A.S. Gorshkov, Magazine of Civil Engineering, 4, 21-25 (2009)

9. Dzh. Uiktn, E. Skal, Fiber composite materials (Metallurgy, Moscow,1978)

10. T.S. Morozov, V.D. Kuznetsov, Magazine of Civil Engineering, 3, 35-38 (2010) 
11. A.L. Shagin, No. 924317 Bull. Inventions, 16,1, 50 (1982)

12. R.V. Lesovik, S.V. Klyuyev, Magazine of Civil Engineering, 3, 41-98 (2012)

13. N.Yu. Makusheva, N.B. Kolosova, Construction of Unique Buildings and Structures, 10 (25), 60$72(2014)$

14. Interstate standard GOST 31938-2011 "Reinforcing composite polymer for the reinforcement of concrete structures. General specifications"

15. Dzh. Lyubin, Handbook of composites (Metallurgy, Moscow, 1988)

16. Standart. Rulebook Construction of concrete with composite non-metallic reinforcing. Design Rules

17. M. Grosse, R. Hartnack, S. Lehmann, K. Rautenstrauch, Modelling of timber-concrete composites connected only at a few discrete points( Bauhaus-Universität Weimar, Berlin, 2011)

18. B.A. Muralidhar, Materials and Design, 52, 835-840 (2013)

19. B. Kovačič, R. Kamnik, International Journal for Engineering Modelling, 20 (1-4), 77-84 (2007).

20. N.K. Tsirlin, Continuous inorganic fibers for composite materials (Metallurgy, 1992)

21.Z.S. Teplova, S.S. Kiski, D.V. Nemova, A.V. Sokolov, Construction of Unique Buildings and Structures, 4 (19), 62-74 (2014)

22. B. Kovačič, R. Kamnik, Z. Kapović, Geodetski List, 63 (4), 315-327 (2009)

23. B. Kovačič, R. Kamnik, A. Štrukelj, Promet - Traffic - Traffico, 22 (1), 15-22 (2010)

24. Y. Barabanshchikov, S. Belyaeva, A. Avdeeva, M. Perez, Applied Mechanics and Materials, 726, 475-481 (2015)

25. B. Kovačič, R. Kamnik, M. Premrov, N. Gubeljak, J. Predan, Z. Tišma, Strojniski Vestnik/Journal of Mechanical Engineering, 54 (5), 364-371 (2008)

26. B. Kovačič, R. Kamnik, M. Premrov, Survey Review, 43 (320), 150-161 (2011)

27. Abbasi, P.J. Hogg, Composites Part B:Engineering, 36, 5, 394-404 (2005)

28. A.R. Gizdatullin, V.G. Khozin, A.N. Kuklin, A.M. Khusnutdinov, Magazine of Civil Engineering, 3, 40-50 (2014)

29. B. Kovačič, R. Kamnik, A. Štrukelj, N. Vatin, Procedia Engineering, 117 (1), 800-806 (2015)

30. B . Kovačič, B. Geodetski Vestnik, 48 (1), 32-39 (2004) 